\title{
Assessing the effectiveness of an occupational health and safety system in a selected automotive assembly organisation in South Africa
}

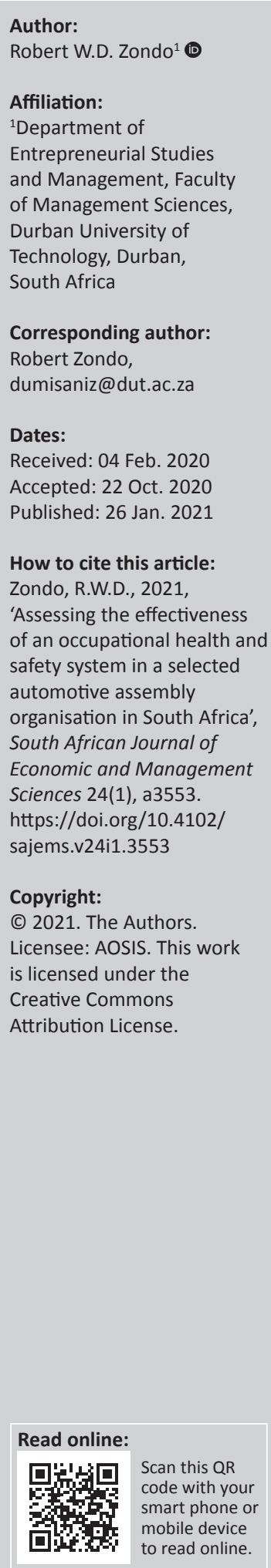

Background: It has been established that high levels of safety performance are achieved by strong and positive safety climates. Good safety, health and environmental practices reduce the cost of overall healthcare delivery while increasing general productivity. These sentiments underpin the concept of an occupational health and safety (OHS) system.

Aim: This study assesses the effectiveness of an OHS in a selected automotive assembly organisation in South Africa.

Settings: The automotive organisation that participated in the study has adopted an OHS system. Prior to its implementation, the company experienced an increase in the rate of occupational diseases and injuries.

Methods: The study objectives were achieved by examining Health and Safety (H\&S) related experiences in the company. The collection of data was carried out in two phases, namely the collection of pre-OHS and post-OHS results from company records for H\&S compliance, occupational diseases, as well as workplace injury rates. The pre-OHS results were quarterly data reflecting the company's H\&S performance over the 3-year period prior to the implementation of the OHS system. This company operates in the eThekwini District Municipality in KwaZulu-Natal.

Results: The OHS system has no influence on occupational diseases, or on the workplace injury frequency rates. However, H\&S compliance plays a role in the maintenance of the OHS system.

Conclusion: In order to maximise performance, a comprehensive OHS policy must be developed that aligns management commitment to the OHS system. Thus, the study uncovered the strengths and weaknesses of OHS in this automotive assembly organisation in South Africa.

Keywords: automotive assembly organisation; employee compliance; health and safety; occupational disease; workplace injury; workplace safety.

\section{Introduction}

It has been established that some of the key business strategies that aim at maintaining competitiveness include rebranding to fit the required international standards, increased innovation through research and development, as well as re-profiling operations to respond to the changes in business environment (Bonini \& Görner 2011). An effective safety management system (SMS) is one of the strategies for meeting international standards (Phusavat et al. 2017). With increasing complexity in the industrial sector, the increase in accidents and the speed with which techniques evolve in large companies, risk management becomes a decisive and strategic response to safeguard workers' health and safety (H\&S) (Dodge 2012). Every year, thousands of people across businesses are the victims of workplace accidents or develop serious health problems in the workplace. In Kuwait, more than 51500 work-related accidents are recorded each year, causing a social safety bill of more than 29 billion dinars (or US\$94.83 billion) in 2016, against 20 billion dinars (or US $\$ 65$ billion) for 2014 (Amine \& Antar 2017). These expenditures reveal considerable gaps in occupational health and safety (OHS) that an industrialised country cannot afford.

One area in which the concern for safety is growing rapidly is the manufacturing industry (Adebiyi, Jekayinfa \& Charles-Owaba 2009; Tymvios \& Gambatese 2016). Apart from cost due to 
downtime, overtime work, loss of wages, as well as equipment, the tragedy associated with personal injury, disability and fatality is enormous (Khan et al. 2019). In respect of fatalities, industrial accidents take third place after vehicular accidents and homicide (Conchie \& Donald 2009). In the United States of America (USA), the figure is around 6500 fatalities per year, while the number of deaths together with disabling injuries account for 9 million (Burt, Chmiel \& Hayes 2009). In the United Kingdom (UK), 1.6 million injury accidents and 27 million non-injury accidents are recorded annually (Phusavat et al. 2017). In India, the overall injury rate was 1.25 per 1000 workers per year (Bonini \& Görner 2011). In the Latin America and Caribbean region, the number is as high as 13.5 per 100 000; 34 per 100000 workers in the Republic of Korea and 140 per 1000 in Iran reported accidents (Phusavat et al. 2017). In Finland, 20016 hospitalisations for injuries were recorded between 1990 and 1999 (Rachid et al. 2015); in France 862500 occupational accidents, including 1597 fatalities, were recorded in the year 2000 alone (Conchie \& Donald 2009).

In many nations around the world, regulatory agencies are saddled with the task of ensuring that industry conforms to government safety programme standards (National Safety Council 2008). The National Institute of Occupational Health and Safety in the USA pursues active programmes of research surveillance, prevention interventions, information dissemination and health professional education in order to prevent work-related illness, injury, disability and death (Cesarini, Hall \& Kupiec 2013; National Safety Council 2008). Other agencies with similar responsibilities include European Agency for Safety and Health at Work, European Network for Workplace Health Promotion, Health and Safety Executive, Occupational Safety and Health Administration, American National Standard Institute and Royal Society for Prevention of Accidents (Conchie \& Donald 2009). In addition, the intermediaries such as Small Business Service, Chambers of Commerce, Learning and Skills Councils, Trade and Professional Associations, Health and Safety Consultants and Good Neighbours contribute to the provision of H\&S information, advice and training courses to the industrial sector (National Safety Council 2008 in Amine \& Antar 2017). Despite the large numbers of national and international safety monitoring and enforcement agencies, hazardous conditions are still prevalent in manufacturing. As mentioned earlier, industrial losses of lives, limbs, machine-hours and man-hours of labour and revenue through accidents persist. There seems a significant communication gap between these agencies and the manufacturing industry (Amine \& Antar 2017). While the former may be zealous, calling upon industry to invest in and effectively manage safety programmes, the latter often perceives enforcement of safety standards as cost-increasing. Consequently, rather than comply, they often resist safety regulations.

Considering that H\&S in the workplace is a continual action of improvement, the actions to be undertaken must be prioritised. A prioritisation technique is therefore required that gives stakeholders the level of trust and necessary information to those concerned (Amine \& Antar 2017). It has been established that the manufacturing sector is faced with many OHS challenges (Phusavat et al. 2017), such as stress, sickness and unsafe working practices. Such health abnormalities contribute to absenteeism, illness and injury and a decrease in productivity. Ahmady, Nikooravesh and Mehrpour (2016) add that the common workplace OHS hazards include communicable disease, transportation accidents, workplace violence, slipping and falling, toxic events, particularly chemical and gas exposure, explosion, repetitive motion, ergonomic injuries and hearing loss. Hence, Tymvios and Gambatese (2016) indicate that one of the effective methods of efficient safety management is creating a safety culture within the organisation. Safety culture is defined by Kartikawati and Diunaidi (2018) as the values, beliefs, customs, traditions and methods disseminated by its members. It shapes management and employees' safe behaviour and practices (Cesarini et al. 2013). Consequently, this study explores the suitability of $\mathrm{OHS}$ as an appropriate system for employee compliance to $H \& S$ practices in automotive assembly organisations in South Africa.

The rest of the article discusses the literature that was reviewed in this study, the methodology employed, study results, as well as the discussion of results. In addition, it deliberates on the implications of results for policy and practice, study limitations, conclusion, as well as future research required.

\section{Literature review}

This section discusses an overview of OHS. The OHS climate for business concludes the theoretical framework of the study.

\section{Overview of occupational health and safety}

It seems common sense that everyone in a workplace would do what they can to prevent workplace injury (Rachid et al. 2015). Sadly, the statistics on workplace injury stand as testament to the fact that while effective practices and procedures for ensuring workplace safety exist, and that world-class safe work places do exist (Dodge 2012), safe work standards are far from universally adopted and implemented in workplaces (Amine \& Antar 2017). The analysis of company records on the OHS standard highlighted that effective safety systems and programmes have not been implemented in many workplaces and these missed opportunities could have prevented the suffering and loss resulting from workplace injuries (Phusavat et al. 2017). According to Kartikawati and Djunaidi (2018), considerable research suggests that organisational leaders play a central role in influencing safety-related attitudes and actions in the workplace. Beliefs and assumptions of managers relative to the roles of management and workers regarding workplace safety underlie and direct actions relative to workplace safety (Pagell et al. 2015). 
An underlying assumption that workers are responsible for their own safety, will result in a laissez-faire approach from management to their role in injury prevention (Dodge 2012). Without management commitment to injury prevention, a culture of disregard for safety may exist. Kartikawati and Djunaidi (2018) indicate that while it is unlikely that organisational leaders would admit to being 'anti-safety', or suggest to their employees that they disregard safety protocols, it is possible that in some cases leaders simply ignore safety concerns. Workers and managers do not arbitrarily determine their attitude towards safety. It is developed and nurtured by the workplace context, and past experiences. Managers, through their actions (or inactions) consciously (or unconsciously) define the workplace climate and culture that employees subscribe to, and determine appropriate and acceptable actions and expectations (Lingard, Cooke \& Blismas 2011). In practical terms, this would suggest that workers with a cavalier attitude toward safety, who join companies with a strong commitment to safety, find themselves having to undergo a significant change in perspective and behaviour to fit in. Sadly, the opposite also holds true. People and their behaviours, beliefs, assumptions, knowledge, interpretations and actions are a part of the workplace culture that is infinitely variable (Pagell et al. 2015). However, preventing workplace injury requires commitment and engagement from the senior management level to the front-line employees. The absence of an evident commitment to safety by management leaves employees and supervisors without reference points for decision-making relative to safety expectations (Lingard et al. 2011). Creating and implementing safety systems is an important part of injury prevention. Injury prevention strategies and models must be developed and documented (Khan et al. 2019). However, the OHS cannot function without commitment and engagement on all levels of business. Hence, the next section discusses the expected OHS climate in business.

\section{Occupational health and safety climate in business}

Safety climate is defined as individual perceptions of the policies, procedures and practices relating to safety in the workplace (Khan et al. 2019). It shapes workers' behaviour through the expectations they form about how organisations value and reward safety (Amine \& Antar 2017). A great deal of interest has been given to the extent to which safety climate predicts safety performance within organisations (Kartikawati \& Djunaidi 2018). There is considerable evidence that strong and positive safety climates are linked to higher levels of safety performance. For example, Tharaldsen, Olsen and Rundmo (2008) report a significant inverse correlation between safety climate perceptions and accident rates in the offshore industry, while Lingard et al. (2011) showed that offshore installations returning a lower proportion of selfreported accidents were characterised by more favourable safety climates. Ahmady et al. (2016) report the safety climate to be inversely correlated with the accident rate in woodprocessing companies and, in the Australian health sector,
Amine and Antar (2017) report that safety climate measured at one point in time positively predicted subsequent safety motivation and self-reported safety-related behaviour. Cesarini et al. (2013) conducted a comprehensive metaanalysis of safety climate research and reported a consistent positive link between safety climate and safety performance in prospective studies (that is, those in which safety performance was monitored after the measurement of safety climate was undertaken). Safety climate has also been linked to an organisation's ability to appropriately attribute incident causes and learn lessons from safety incidents (Lingard et al. 2011).

In most industrialised countries, a safety culture and awareness of the positive value of a safe and healthy working environment in terms of economic benefits and social justice are low (Lingard et al. 2011). As seen from the experience in industrialised countries where it took over a century to build a solid safety culture, the progressive integration of safety principles and reflexes is a fundamental prerequisite for any improvement in the reduction of occupational accidents and diseases (Lingard et al. 2011). A long-term implementation of good safety, health and environmental practices, (that is, the continued implantation of a safety culture as an essential part of the more general social or enterprise culture) is the only way to reduce the cost of overall healthcare delivery while increasing general productivity (Phusavat et al. 2017). Occupational health and safety will play a key role in promoting such a culture at company level. As a result, this study investigates whether the OHS system enables employee compliance with H\&S in the automotive assembly sector. It explores the suitability of $\mathrm{OHS}$ as an appropriate system for employee compliance to H\&S.

\section{Hypothesis}

The study is based on the following assumption:

H1: The implementation of the OHS enables employee compliance to $\mathrm{H} \& \mathrm{~S}$ in automotive assembly companies.

$\mathbf{H 1}_{\mathbf{0}}$ : The implementation of OHS does not enable employee compliance to H\&S in automotive assembly companies.

The following are sub-hypotheses:

H2: An increase in the rate of occupational diseases increases employee compliance in automotive assembly companies.

$\mathrm{H}_{\mathbf{0}}$ : An increase in the rate of occupational diseases decreases employee compliance in automotive assembly companies.

H3: An increase in the workplace injury frequency rate increases employee compliance in automotive assembly companies.

$\mathrm{H}_{0}$ : An increase in the workplace injury frequency rate decreases employee compliance in automotive assembly companies

\section{Methodology}

The method for this research will be discussed under the following headings: research design and approach, company that participated in the study, data collection, as well as the measurement and data analysis. 


\section{Research design and approach}

This study was quantitative in nature. It examines employee compliance in H\&S as a dependent variable to occupational diseases, as well as the workplace injury frequency rates. Bryman and Bell (2007) explain that the quantitative approach involves the use of statistical procedures to analyse the data collected. Consequently, after the measurements of the relevant variables, the scores were transformed using statistical methods. In addition, the study adopted a panel data analysis. According to Curwin and Slater (2002), panel data analysis is the statistical analysis of data sets consisting of multiple observations on each sampling unit. It contains more degrees of freedom and less multicollinearity than cross-sectional data, thus improving the efficiency of econometric estimates (Bryman \& Bell 2007). For this study, the pre-OHS and post-OHS data that were collected over time from the automotive assembly organisation were analysed using the regression model. The study was also conclusive in design. Conclusive studies are meant to provide information that is useful in decisionmaking (Yin 2008).

\section{Company that participated in the study}

A convenience sample from one large automotive assembly company situated within the eThekwini District Municipality in the province of KwaZulu-Natal in South Africa was used. The company had adopted an OHS system and agreed to participate in the study. It is labour intensive and, prior to OHS implementation, it experienced frequent rates of occupational diseases and injuries. The frequency rate of workplace injuries ranged between $1.75 \%$ and $10.58 \%$ per quarter. This includes injuries related to pulling, lifting, pushing, holding, carrying, and throwing activities at work. These types of injuries included slipping, tripping and falling, muscle strains, cuts, as well as repetitive strains. Furthermore, the rate for occupational-related diseases ranged between $4 \%$ and $25 \%$ per quarter. These included hearing loss as a result of noise and hazardous chemical substance exposure. The company had 1403 employees. It operates a three-shift system. Table 1 presents both the percentage and frequency breakdown of employees in terms of their level of activities.

\section{Data collection}

The collection of data from a single company that participated in the study was carried out in two phases: the collection of pre-OHS and post-OHS results by a H\&S team leader from the operational records on occupational-related diseases and injuries. The data for occupational diseases and workplace

TABLE 1: Percentage and frequency breakdown of employees in terms of their level of activities.

\begin{tabular}{llcc}
\hline Number & Level of activity & $\%$ & Frequency \\
\hline 1. & Plant management & 3.1 & 43 \\
2. & Support administration staff & 11.0 & 154 \\
3. & Team leaders & 5.2 & 73 \\
4. & Line functional employees & 80.7 & 1133 \\
\hline
\end{tabular}

injury frequency rates were kept on the System, Applications and Products (SAP) version 6.0 data management programme. The collection of such data over time provided a greater capacity for capturing the complexity of H\&S compliance changes than using the one group post-test design that involves the collection of only the post-data after the changes have been implemented, resulting in threats to internal validity (Bryman \& Bell 2007). The validation of data from SAP was done by the researcher. This was achieved by comparing data from SAP with the documented data kept on files for accuracy.

The pre-OHS results were quarterly data reflecting the company's performance over the 3-year period prior to OHS implementation. This included data from the first quarter of 2013 to the final quarter of 2015. The post- OHS data reflected the company's performance for 2 years after OHS was implemented. This included data from the first quarter of 2016 to the final quarter of 2017.

\section{Measurement and data analysis}

The company's quarterly time series data on occupational diseases and workplace injury frequency rate were used. The measurements were based on a total of 96 observations. According to Westland (2010), there is no rule regarding the minimum number of observations for a balanced data panel. However, 50 observations are acceptable but more than 100 is recommended (Bryman \& Bell 2007). The regression model used was of the ordinary least square (OLS) variety. The choice was influenced by data constraints. However, the model provided the statistical method that enabled the researcher to examine the relationship between the variables effectively.

A dummy variable which assumed the value of 0 and 1 to represent the pre-OHS and post-OHS was introduced into the OLS model. The aim was to isolate the pre-OHS and post-OHS effects. Consequently, if OHS proved to be a useful strategy in enabling employees to comply with H\&S regulations, this would result in a statistically significant coefficient on the dummy variable.

The OLS model used was as follows: H\&S compliance $=\mathrm{B}_{0}+\mathrm{B}_{1}$ Occupational diseases $+\mathrm{B}_{2}$ Workplace injury frequency rate $+\mathrm{B}_{3}$ Pre/Post-Dummy, where $\mathrm{B}_{0}$ is the constant and $\mathrm{B}$ is the coefficient of the independent variables

The above model identifies H\&S as a function of occupational disease, workplace injuries and the OHS system. Data were analysed using the statistical package for social sciences (SPSS) version 25. It enabled the H\&S data that were obtained, quarterly, over the multiple time periods from the same operational division to be appropriately analysed. Hence, the results provided unbiased estimations (Yin 2008). Furthermore, the OLS was based on the fixed effects model, in which the model parameters are fixed (that is, non-random quantities) (Curwin \& Slater 2002). Consequently, the variables were collected, quarterly, from the first quarter of 2013 to the last quarter of 2017 from the same company. 
TABLE 2: Normality tests for health and safety compliance, occupational diseases, as well as workplace injury frequency rate.

\begin{tabular}{lccccccc}
\hline Variable & \multicolumn{3}{c}{ Kolmogorov-Smirnov $\dagger$} & \multicolumn{3}{c}{ Shapiro-Wilk } \\
\cline { 2 - 8 } & Group & Statistic & $\boldsymbol{d f}$ & Significance & Statistic & $\boldsymbol{d f}$ & Significance \\
\hline Health and safety & 0 & 0.120 & 8 & $0.200 \ddagger$ & 0.976 & 8 & 0.939 \\
compliance & 1 & 0.172 & 8 & $0.200 \ddagger$ & 0.960 & 8 & 0.806 \\
Occupational & 0 & 0.202 & 8 & $0.200 \ddagger$ & 0.843 & 8 & 0.080 \\
diseases & 1 & 0.300 & 8 & 0.033 & 0.798 & 8 & 0.027 \\
Workplace injury & 0 & 0.330 & 8 & 0.011 & 0.719 & 8 & 0.004 \\
frequency rate & 1 & 0.337 & 8 & 0.008 & 0.725 & 8 & 0.004 \\
\hline
\end{tabular}

$\dagger$, Lilliefors Significance Correction; $\ddagger$, This is a lower bound of the true significance.

The statistical tests showed that data were normally distributed ( $p>0.05)$. Hence, the study results were analysed using parametric tests, that is, the $t$-tests.

For this study to achieve its objectives, the normality tests were then conducted using Kolmogorov-Smirnov and Shapiro-Wilk for the overall score of the constructs. Table 2 presents results for normality tests for H\&S compliance, occupational diseases and workplace injury frequency rate.

\section{Study results}

This section presents results for pre-OHS and post-OHS means comparison, as well as H\&S.

\section{Pre- and post-occupational health and safety means comparison}

Table 3 compares the means (in percentages) for H\&S compliance, occupational diseases and workplace injuries.

Table 3 indicates that the percentage mean data for pre-OHS for H\&S compliance, occupational diseases and workplace injuries were $87.3 \%, 15 \%$ and $3.4 \%$. However, the percentage mean data for post-OHS for H\&S compliance, occupational diseases and workplace injuries were $99.4 \%, 16 \%$ and $1.4 \%$. Table 3 shows mixed results of mean values on the three variables (that is, H\&S compliance, occupational disease and workplace injury frequency rate) from pre-OHS mean data to post-OHS mean data. However, they show a decrease in mean values on workplace injury frequency rates when post$\mathrm{OHS}$ is compared with the pre-OHS periods. This indicates the influence of OHS in the organisation that participated in the study. Consequently, the next section assesses H\&S results as a consequence of OHS implementation.

\section{Health and safety results}

Table 4 presents the results for H\&S as a dependent variable to occupational disease, workplace injury frequency rate, as well as post-OHS dummy.

\section{Health and safety compliance as a dependent variable to occupational diseases}

The results in Table 4 show that the number of occupational diseases has no relationship with H\&S compliance, thus accepting the null hypothesis of no relationships between these two variables. This is determined by its $t$-value of 1.405 , as well as the $p$-value of 0.185 . The $t$-value is below the critical value of 2.021 at the $5 \%$ level of significance
TABLE 3: Pre- and post-occupational health and safety percentage means comparison.

\begin{tabular}{lccc}
\hline Variable & $\begin{array}{c}\text { Pre-OHS } \\
\text { period (\%) }\end{array}$ & $\begin{array}{c}\text { Post-OHS } \\
\text { period (\%) }\end{array}$ & $\begin{array}{c}\text { Mean difference } \\
\text { (pre - post) (\%) }\end{array}$ \\
\hline Health and safety compliance & 87.3 & 99.4 & -12.1 \\
Occupational diseases & 15.0 & 16.0 & -1.0 \\
Workplace injury frequency rate & 3.4 & 1.4 & +2.0 \\
\hline
\end{tabular}

OHS, Occupational health and safety.

TABLE 4: Compliance results for health and safety as a dependent variable to occupational disease, workplace injury frequency rate, as well as postoccupational health and safety dummy.

\begin{tabular}{lccc}
\hline Regression & Coefficient & $t$-statistic & Probability \\
\hline Constant $\left(\mathrm{B}_{0}\right)$ & -6.478 & -13.226 & 0.000 \\
$\begin{array}{l}\text { Occupational disease } \\
\begin{array}{l}\text { Workplace injury } \\
\text { frequency rate }\end{array}\end{array}$ & 0.006 & 1.405 & 0.185 \\
$\begin{array}{l}\text { Occupational health } \\
\text { and safety dummy }\end{array}$ & -0.025 & -1.692 & 0.117 \\
$R$-squared & 0.959 & 14.446 & 0.000 \\
$\begin{array}{l}\text { Adjusted } R^{2} \\
\begin{array}{l}\text { Standard error of } \\
\text { regression }\end{array}\end{array}$ & 0.948 & F-statistics & 92.799 \\
\hline
\end{tabular}

Note: Regression data: $2013-2017$ for 96 observations. The following OLS estimation is based on the equation: $\mathrm{H} \& S=B_{0}+B_{1}$ Occupational diseases $+B_{2}$ Workplace injury frequency rate $+B_{3}$ Pre/Post-Dummy.

(Curwin \& Slater 2002) and the $p$-value is above the 0.05 level. Pagell et al. (2015) indicate that work-related diseases have multiple causes, where factors in the work environment may play a role, together with other risk factors, in the development of such diseases.

\section{Health and Safety compliance as a dependent variable to workplace injury frequency rate}

Results as illustrated in Table 4 show that the workplace injury frequency rate has no relationship with $H \& S$ compliance, thus accepting the null hypothesis of no relationships between these two variables. This is determined by its $t$-value of -1.692 , as well as the $p$-value of 0.117 . The $t$-value is below the critical value of 2.021 at the $5 \%$ level of significance and the $p$-value is above the 0.05 level. Dodge (2012) concurs with the results, in that the common workplace injuries are mainly caused by sprains, strains and tears by employees. However, Amine and Antar (2017) indicate that over-exertion and bodily reaction, slips, trips and falls, as well as contact with objects and equipment account for more than $84 \%$ of all non-fatal injuries.

\section{Health and safety compliance as a dependent variable to occupational health and safety dummy variable}

Results show that H\&S compliance has a relationship and is statistically significant to OHS system as shown by its $t$-value of 14.446 , which is above the critical $t$-value of 2.021 at the $5 \%$ level of significance, thus accepting the null hypothesis of a relationship between these two variables. It has an adjusted $\mathrm{R}^{2}$ of 0.948 , which implies that the OHS system accounts for approximately $95 \%$ of variance for H\&S compliance. In addition, the serial correlation is high at 1.825 when compared to the standard value of 1.72 at the $5 \%$ level of significance (Curwin \& Slater 2002). Pagell et al. (2015) indicate that H\&S compliance prevents workplace illnesses and injuries, and reduces health and safety hazards. Organisations that have implemented an OHS system keep their premises to higher safety standards (Phusavat et al. 2017). 


\section{Summary of results: Statistical tests and box plots for determining whether the normality and homogeneity of variances have been met}

This section analyses data using factorial designs. It incorporates box plots to determine whether the factorial ANOVA assumptions of normality and homogeneity of variances have been met. Porkess (2005) explains that the populations represented should be normally distributed (that is, the normality), making the mean an appropriate measure of central tendency. However, the homogeneity of variance indicates that the population from which the data are sampled should have the same variance.

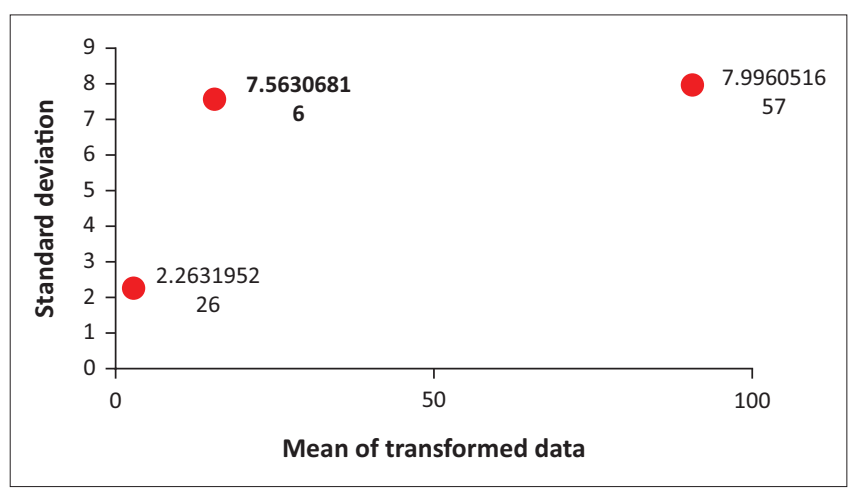

FIGURE 1: Bartlett's test for homogeneity of variances.

\begin{tabular}{lccc} 
TABLE 5: Bartlett's test for homogeneity of variances. & & \\
\hline Variables & $\begin{array}{c}\text { Means of } \\
\text { transformed data }\end{array}$ & $\begin{array}{c}\text { Standard deviations } \\
\text { of transformed data }\end{array}$ & $p$ \\
\hline Health and safety compliance & 15.5 & 7.563 & 0.001 \\
Occupational diseases & 90.6 & 7.996 & 0.001 \\
Workplace injury frequency rate & 2.73 & 2.263 & 0.001 \\
\hline
\end{tabular}

TABLE 6: Levene's test of equality.

\begin{tabular}{lcc}
\hline Fisher-Snedecor & $\boldsymbol{t}$-statistic & Significance \\
\hline 28.470 & -9.911 & 0.000 \\
\hline
\end{tabular}

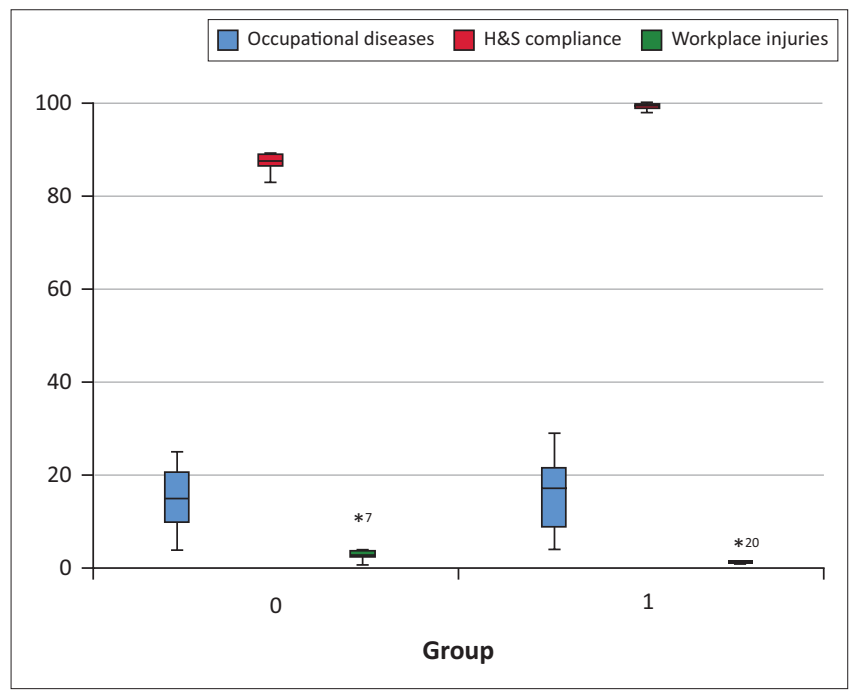

FIGURE 2: Box plots determining the normality and homogeneity of variance.
The Bartlett's test was used to verify whether the variances were equal for all the samples (Curwin \& Slater 2002). Figure 1 shows the summary of the results from the Bartlett's test for homogeneity of variances.

However, Table 5 presents detailed results of Bartlett's test for homogeneity of variances for H\&S compliance, occupational diseases, as well as workplace injury frequency rate.

The $p$-value in Table 5 of the Bartlett's test shows that the homogeneity of variances has occurred, thus rejecting the null hypothesis. The $p$-value at 0.001 is low when compared with the significance level of 0.05 . We can conclude that there are distribution changes between the two parts of time series. This is confirmed by Levene's test of equality, shown in Table 6.

Porkess (2005) defines Levene's tests of equality as an inferential statistic used to assess the equality of variance on different samples. In Levene's test of equality, the statistical procedure assumes that variances of the populations from which different samples are drawn are equal. Consequently, the results in Table 6 show that the obtained similarities between the variances in the samples for pre- and post-data at $p$-value 0.000 have occurred. They are below the statistically significant level of 0.05 . The results are confirmed by box plots in Figure 2.

Different options of $t$-test revolve around the assumption of equal or unequal variances (Westland 2010). Hypothetically, any F-test can be regarded as a comparison of two variances. Thus, the test statistic for this study represents the ratio of two sample variances. Consequently, the box plots in Figure 2 show a similar spread of H\&S results. They indicate that the mode of change from pre-OHS to post-OHS period is homogeneous.

The statistical tests suggest that the conditions for homogeneity of variances between the pre-OHS and post-OHS have been met.

\section{Discussion}

This study assesses the effectiveness of an OHS system in an automotive assembly organisation in South Africa that has adopted the system. Quarterly time series data on H\&S compliance, occupational-related diseases and workplace injury frequency rates were used to analyse data. Results from this study indicate that the H\&S compliance has no relation to either the occupational-related diseases or workplace injury frequency rates. Dodge (2012) indicates that, while effective practices and OHS procedures for ensuring workplace safety exist, the safe work standards in companies are far from adopted and properly implemented in workplaces. Other than implementing the OHS system, Lingard et al. (2011) indicate that preventing workplace injuries requires commitment and engagement from the 
senior management level to the front-line employees. Thus, H\&S regulations become paramount to the well-being of the employees and the employer. The study also revealed the relationship of H\&S compliance with the OHS system. According to Kartikawati and Djunaidi (2018), the OHS system must be a top priority for an organisation to implement the workplace H\&S measures for their employees. It is mandatory by law to ensure that the employees are aware of all the safety measures. It prevents hazards that can happen in the workplace, as well as the costs of neglecting the H\&S to employees. It is a system that protects employees from injury, occupational illness, disability or death (Amine \& Antar 2017).

\section{Implications of results for policy and practice}

Organisations in South Africa should develop OHS strategies, policies and practices that help to achieve new business goals and support organisational and cultural change (Kelloway, Francis \& Montgomery 2006). Managers, through their actions, should consciously define the workplace climate and culture that employees respect and determine appropriate and acceptable actions and expectations for the OHS before it is implemented (Lingard et al. 2011). Besides the achievement of study objectives, the following conclusions can be made on the OHS system:

- A long-term implementation of good OHS is the only way to reduce the cost of overall healthcare delivery (Phusavat et al. 2017).

- Management commitment to injury prevention creates an effective safety culture for organisations.

- In order to maximise performance, a comprehensive OHS policy must be developed, that aligns management commitment to the OHS system and H\&S compliance (Lingard et al. 2011).

Management should recognise the importance of H\&S procedures in the workplace in order to reduce employee illnesses and injuries, as well as H\&S hazards (Kartikawati \& Djunaidi 2018). The OHS system helps organisations keep premises to higher safety standards (Phusavat et al. 2017).

\section{Study limitations}

The study was limited to an automotive assembly company operating within the eThekwini District Municipality. The investigation was conducted in a single company that has adopted an OHS system. As there are eight registered assembly companies in South Africa (SAinfo 2018), the results cannot be extrapolated to other companies within the sector. Secondly, it did not examine the process followed during the OHS implementation including (among others) the individuals that participated in the implementation process. It used only quarterly time series data to determine the pre and post effects resulting from the OHS system. Lastly, the econometrics model used was of the OLS variety, solely due to data constraints. Future studies ought to use the more advanced Johansen VAR methodology or panel data analysis, both of which rely on large data sets.

\section{Conclusion}

OHS is an appropriate system that ensures that both workplace safety and world-class safe workplaces exist (Phusavat et al. 2017). Properly implemented and managed, the system results in employee safety in the workplace. Consequently, there is considerable evidence that strong and positive safety climates are linked to higher levels of safety performance (Dodge 2012). For example, Tharaldsen et al. (2008) report a significant inverse correlation between safety climate perceptions and accident rates. Thus, the study revealed the relationship with H\&S compliance and the OHS system in the selected automotive assembly company. The OHS system prevents damages to the organisation's assets and the general workplace environment (Khan et al. 2019). However, management must show commitment to the system. Without management commitment to injury prevention, a culture of disregard for safety may exist (Dodge 2012).

\section{Future research required}

During the course of this study, issues relating to the long-term survival of an OHS system after implementation were not covered. These include the applicability of OHS to a wider sector of economic activity, including the public sector. The nature of this research did not allow these areas to be covered in depth. It is recommended that future research should examine the following issues in greater depth:

- When to use and when not to use the OHS system.

- The applicability of an OHS approach to other industrial sectors.

- The process followed during the implementation of the OHS system.

- A more comprehensive investigation should be carried out using a randomised sample of the registered automotive companies that use the OHS system to see if the results can be generalised.

The study investigated the effectiveness of OHS in a selected automotive assembly organisation in South Africa. The preOHS and post-OHS quarterly data from company records were collected. It established that the OHS system has no influence on occupational diseases or on workplace injury frequency rates. However, H\&S compliance plays a role in the maintenance of the OHS system.

\section{Acknowledgements}

The author thanks the organisation for granting permission to conduct the study.

\section{Competing interests}

The author has declared that no competing interests exist. 


\section{Author's contributions}

The author, R.W.D.Z., declares that he is the sole author of this research article. He administrated the questionnaire, worked on the literature review, analysed the raw data, aligned and consolidated the article into a final manuscript.

\section{Ethical consideration}

This article followed all ethical standards for research.

\section{Funding information}

The article will be paid for by the researcher funds kept by the Durban University of Technology (DUT).

\section{Data availability statement}

The authors confirm that the data supporting the findings of this study are available within the article.

\section{Disclaimer}

The views and opinions expressed in this article are those of the authors and do not necessarily reflect the official policy or position of any affiliated agency of the authors.

\section{References}

Adebiyi, K.A., Jekayinfa, S.O. \& Charles-Owaba, O.E., 2009, 'Appraisal of safety practices in agro-allied industries in Southwestern Nigeria', Disaster Prevention and Management - An International Journal 14(1), 80-88. https://doi.org/ and Management - An Inte
$10.1108 / 09653560510583842$

Ahmady, G.A., Nikooravesh, A. \& Mehrpour, M., 2016, 'Effect of organizational culture on knowledge management based on Denison model', Procedia - Social and Behavioral Sciences 230, 387-395. https://doi.org/10.1016/j.sbspro.2016.09.049

Amine, S. \& Antar, G., 2017, Discerner les risques qui méritent d'être poursuivis en entreprise; mémoire de master en hygiène et sécurité industrielle de l'Universite des frères mentouri Constantine, Journal of Materials Chemistry B, London.

Bonini, S. \& Görner, S., 2011, 'The business of sustainability: Mckinsey global survey results', October, viewed 15 August 2018, from www.mckinsey.com/businessfunctions/sustainability-and-resourceproductivity/our-insights/the-business-ofsustainability-mckinsey-global-survey-results.

Burt, D.B., Chmiel, N. \& Hayes, P., 2009, 'Implications of turnover and trust for safety attitudes and behaviour in work teams', Safety Science 47(1), 1002-1005. https:// doi.org/10.1016/j.ssci.2008.11.001

Bryman, A. \& Bell, E., 2007, Business research methods, Oxford Press, New York.
Cesarini, G., Hall, G. \& Kupiec, M., 2013, Building a proactive safety culture in the construction industry, 2nd edn., ACE Construction, Florence.

Conchie, S.M. \& Donald, I.J., 2009, 'The moderating role of safety-specific trust on the relation between safety-specific leadership and safety citizenship behaviors', Journal of Occupational Health Psychology 14(1), 137-147. https://doi.org/ 10.1037/a0014247

Curwin, J. \& Slater, R., 2002, Quantitative methods for business decisions, British Library Cataloguing Data, London.

Dodge, R.B., 2012, 'Patterns of root cause in workplace injury', International Journal of Workplace Health Management 5(1), 31-43. https://doi.org/10.1108/1753835 1211215375

Kartikawati, M. \& Djunaidi, Z., 2018, 'Analysis of safety culture maturity level in construction at MK Gelora Bung Karno Main Stadium renovation project', International Conference of Occupational Health and Safety (ICOHS-2017), Bali, 1-2 November, pp. 348-360.

Kelloway, K., Francis, I. \& Montgomery, M., 2006, Management of occupational health and safety, 3rd edn., Thompson Nelson, Toronto.

Khan, M.W., Ali, Y.D., Felice, F. \& Petrillo, A., 2019, Occupational health and safety in construction industry in Pakistan using modified-SIRA method, viewed 20 August 2019, from www.elsevier.com/locate/safety.

Lingard, H., Cooke, T. \& Blismas, N., 2011, 'Co-workers' response to occupational health and safety: An overlooked dimension of group-level safety climate in the construction industry', Engineering, Construction and Architectural Management 18(2), 159-175. https://doi.org/10.1108/09699981111111139

National Safety Council, 2008, Injury facts, CD-ROM, National Safety Council, Itasca, IL.

Pagell, M., Klassen, R., Johnston, D., Schevchenko, A. \& Sharma, S., 2015, 'Are safety and operational effectiveness contradictory requirements: The roles of routines and relational coordination', Journal of Operations Management 36, 1-14.

Phusavat, K., Vongvitayapirom, B., Kess, P. \& Lin, B., 2017, 'Safety management system in automotive and energy industries', International Journal of Quality \& Reliability Management 34(4), 569-580. https://doi.org/10.1108/IJQRM-08Reliability

Porkess, R., 2005, Collins internet-linked dictionary of statistics, HarperCollins, Glasgow.

Rachid, C., Ion, V., Irina, C. \& Mohamed, B., 2015, Preserving and improving the safety and health at work: Case of Hamma Bouziane cement plant (Algeria), vol. 76, pp. 145-150, Safety Science, Science Direct, Elsevier, London.

SAinfo, 2018, South Africa's automotive industry, viewed 14 February 2019, from http://www.southafrica.info/doing_business/economy/key_sectors/ motorindustryboost.html.

Sobhani, A., Wahab, M.I. \& Neumann, W.P., 2015, 'Investigating work-related ill health effects in optimizing the performance of manufacturing systems', European Journal of Operational Research 241(3), 708-718. https://doi.org/10.1016/j. ejor.2014.09.032

Tharaldsen, J.E., Olsen, E. \& Rundmo, T., 2008, 'A longitudinal study of safety climate on the Norwegian continental shelf', Safety Science 46(1), 427-439. https://doi. org/10.1016/j.ssci.2007.05.006

Tymvios, N. \& Gambatese, J., 2016, 'Direction for generating interest for design for construction worker safety - A delphi study', Journal of Construction Engineering and Management 142(8). https://doi.org/10.1061/(ASCE)CO.1943-7862.0001134

Westland, J.C., 2010, 'Lower bounds on sample size in structural equation modelling', Electronic Commerce Research and Applications 9(6), 476-487. https://doi. org/10.1016/j.elerap.2010.07.003

Yin, R.K., 2008, Handbook of Applied Research: California, Sage, Thousand Oaks, CA. 